\title{
Do fundamental fears differentially contribute to pain- related fear and pain catastrophizing? An evaluation of the sensitivity index
}

Citation for published version (APA):

Vancleef, L. M. G., Peters, M. L., Roelofs, J., \& Asmundson, G. J. (2006). Do fundamental fears differentially contribute to pain-related fear and pain catastrophizing? An evaluation of the sensitivity index. European Journal of Pain, 10, 527-36. https://doi.org/10.1016/j.ejpain.2005.07.006

Document status and date:

Published: 01/01/2006

DOI:

10.1016/j.ejpain.2005.07.006

Document Version:

Publisher's PDF, also known as Version of record

Document license:

Taverne

Please check the document version of this publication:

- A submitted manuscript is the version of the article upon submission and before peer-review. There can be important differences between the submitted version and the official published version of record.

People interested in the research are advised to contact the author for the final version of the publication, or visit the DOI to the publisher's website.

- The final author version and the galley proof are versions of the publication after peer review.

- The final published version features the final layout of the paper including the volume, issue and page numbers.

Link to publication

\footnotetext{
General rights rights.

- You may freely distribute the URL identifying the publication in the public portal. please follow below link for the End User Agreement:

www.umlib.nl/taverne-license

Take down policy

If you believe that this document breaches copyright please contact us at:

repository@maastrichtuniversity.nl

providing details and we will investigate your claim.
}

Copyright and moral rights for the publications made accessible in the public portal are retained by the authors and/or other copyright owners and it is a condition of accessing publications that users recognise and abide by the legal requirements associated with these

- Users may download and print one copy of any publication from the public portal for the purpose of private study or research.

- You may not further distribute the material or use it for any profit-making activity or commercial gain

If the publication is distributed under the terms of Article $25 \mathrm{fa}$ of the Dutch Copyright Act, indicated by the "Taverne" license above, 


\title{
Do fundamental fears differentially contribute to pain-related fear and pain catastrophizing? An evaluation of the sensitivity index
}

\author{
Linda M.G. Vancleef ${ }^{\text {a,* }}$, Madelon L. Peters ${ }^{\text {a }}$, Jeffrey Roelofs ${ }^{\text {a }}$, \\ Gordon J.G. Asmundson ${ }^{b}$ \\ a Department of Medical, Clinical and Experimental Psychology, Maastricht University, Universiteitssingel 50, P.O. Box 616, \\ 6200 MD Maastricht, The Netherlands \\ b Anxiety and Illness Behaviours Laboratory, University of Regina, Regina, SK, Canada
}

Received 14 December 2004; accepted 27 July 2005

Available online 3 October 2005

\begin{abstract}
Three fundamental fears - anxiety sensitivity (AS), injury/illness sensitivity (IS) and fear of negative evaluation (FNE) - have been proposed to underlie common fears and psychopathological conditions. In pain research, the relation between AS and (chronic) pain processes was the subject of several studies, whereas the possible role of IS has been ignored. The current research examines the role of IS with respect to various pain-related variables in two studies. In the first study, 192 healthy college students completed the Sensitivity Index (SI; a composite measure assessing the three fundamental fears) and various pain-related questionnaires. In a second study, 60 students out of the original sample took part in a pain induction procedure and completed the SI as well. We first examined the properties of the SI. Factor analysis on the SI replicated the proposed factor structure [Taylor S. The structure of fundamental fears, J Behav Ther Exp Psychiat 1993;24:289-99]. However, some items of the ASI did show problematic loadings and were therefore excluded in subsequent analyses. The main hypothesis of the current study states that IS is a stronger predictor than AS of pain catastrophizing and fear of pain as assessed by self-report measures, and of pain tolerance and anticipatory fear of pain as assessed in a pain induction study. This hypothesis could be confirmed for all variables, except for pain tolerance, which was not predicted by any of the three fundamental fears. The current study can be considered as an impetus for devoting attention to IS in future pain research. (c) 2005 European Federation of Chapters of the International Association for the Study of Pain. Published by Elsevier Ltd. All rights reserved.
\end{abstract}

Keywords: Fundamental fears; SI; Fear of pain; Pain catastrophizing

\section{Introduction}

Anxiety sensitivity (AS), or the fear of anxiety symptoms (e.g., heart palpitations) arising from the belief that these symptoms will lead to harmful somatic, psychological or social consequences (Reiss et al., 1986),

\footnotetext{
* Corresponding author. Tel.: +31 43 3881611; fax: +31 43 3884155/ 1601.

E-mail address: L.Vancleef@dmkep.unimaas.nl (L.M.G. Vancleef).
}

has been suggested as an important personality trait in the development and maintenance of chronic musculoskeletal pain (Asmundson and Norton, 1995). AS was found to be directly associated with fear of pain, and indirectly with pain-specific avoidance behaviour, irrespective of pain intensity and pain severity, in patients with chronic musculoskeletal pain (Asmundson and Norton, 1995; Asmundson and Taylor, 1996). Furthermore, elevated levels of AS influenced the pain experience, in response to a pain induction task, and appeared to be a stronger predictor than fear of pain

1090-3801/\$32 @ 2005 European Federation of Chapters of the International Association for the Study of Pain. Published by Elsevier Ltd. All rights reserved.

doi:10.1016/j.ejpain.2005.07.006 
for pain responses following a cold pressor task (Keogh and Birkby, 1999; Keogh and Mansoor, 2001; Greenberg and Burns, 2003).

AS is considered as one of three fundamental fears (or sensitivities), together with injury/illness sensitivity (IS) and fear of negative social evaluation (FNE) (Reiss, 1991; Reiss et al., 1988; Reiss et al., 1986; Taylor, 1993, 1995). A fear is defined as fundamental when it satisfies two criteria: (1) it is a fear of inherently noxious stimuli, and (2) other common fears (e.g., fear of snakes, spiders, or heights) can be logically reduced to the fundamental fear (Reiss, 1991). The distinction between common fears and fundamental fears lies in the fact that fundamental fears provide reasons for fearing a wide range of stimuli whereas common fears do not. A person can, for example, be afraid of snakes and heights, but these fears seem unrelated to each other. However, it is possible that both fears arise from a heightened level of AS. That is: they can both originate from the fear of the confrontation with a snake or a height causing a panic attack (Taylor, 1995).

Taylor (1993) performed further research into the three fundamental fears by means of a factor analytic and correlational study. For this purpose, he created a measure that consisted of pooled items for each fear, which formed a questionnaire that was named the Sensitivity Index (SI). In this questionnaire, the items from the Anxiety Sensitivity Index (ASI) (Peterson and Heilbronner, 1987) were included to assess AS, while the Injury/Illness Sensitivity Index (ISI) was incorporated to assess IS. FNE was measured in the SI with the 12-item version of the Fear of Negative Evaluation Scale (Leary, 1983). The resulting SI was subsequently submitted to a factor analytic analysis, which revealed three-factors that corresponded to the three fundamental fears as originally proposed by Reiss (1991). Intercorrelations of the three factors were low, with $r$ s ranging from 0.26 to 0.32 (Taylor, 1993). Pearson correlations between the three factors and common fears revealed that AS was related to agoraphobia, IS to animal fears and blood-injury fears, and FNE to social fears and animal fears. Taylor concluded that the three fundamental fears are indeed distinct from each other, and that they are specifically related to common fears.

It is important to note that the fundamental fears should not be equated to trait anxiety (Lilienfeld, 1996; McNally, 1996; McWilliams and Cox, 2001; Reiss, 1997; Sandin et al., 2001). Lilienfeld (1996) proposed a hierarchical model in which the fundamental fears are lower-order factors that are nested within the higher-order trait anxiety factor. In this hierarchical model, the lower-order factors share sufficient variance with the higher-order factor, while there remains unique variance that is unrelated to trait anxiety. Taylor's analyses revealed that funda- mental fears do indeed account for $41 \%$ of the total variance in trait anxiety, leaving unique variance open that is unrelated to trait anxiety (Taylor, 1993, 1995).

In pain research, most studies have focussed on AS (e.g., Asmundson et al., 2000). However, it may be proposed that IS plays a more fundamental role than AS in the maintenance and exacerbation of (chronic) health conditions. IS represents the specific fearfulness of imminent injury and illness, and might form a higher-order factor not only of animal fears, but also of other fears that are related to harm to the body and to fear of pain. Recently, Keogh and Asmundson (2004) suggested an adapted version of the hierarchical model outlined by Lilienfeld (1996), in which IS acts as a higher-order factor of painrelated constructs such as fear of pain and pain catastrophizing.

The present study was primarily set up to explore the role of fundamental fears in the explanation of pain-related variables in a healthy population. We choose to conduct the study in a healthy population for two reasons. First, it allows us to compare our results with the results of Taylor (1993), since he used a healthy sample as well. More important, the choice for a healthy population stems from the properties of the ISI. The ISI concerns worrying about getting injured and becoming ill, and is meant to assess a predisposing fear for future injury and/or illness experiences.

In the current research, two studies were set up to further validate the SI in a Dutch student sample and to examine the role of the fundamental fears in their explanation of pain-related variables. In the first study, we examined whether we were able to replicate the threefactor structure of the SI, as it was proposed by Taylor (1993). Also, the associations between the fundamental fears and trait anxiety were examined. The main aim of this study was however to examine the association between the fundamental fears and fear of pain and pain catastrophizing. It is hypothesized that although both AS and IS will be associated with fear of pain and pain catastrophizing, IS will be the strongest predictor of these measures. FNE is not expected to contribute to the explanation of either fear of pain or pain catastrophizing.

The second study examined predictive validity of the fundamental fears using a pain induction procedure. A part of the original sample of study 1 underwent three experimental pain tests and anticipatory fear and pain tolerance for each of these tests was assessed. It is hypothesized that IS will predict anticipated fear and pain tolerance for experimental pain more strongly than AS. FNE is not expected to contribute to the explanation of anticipatory fear or pain tolerance. 


\section{Materials and methods}

\subsection{Participants}

In study 1, 192 students of Maastricht University (42 males and 150 females), with a mean age of 21 ( $\mathrm{SD}=$ 2.55 , range $=18-39$ years), completed a battery of questionnaires, including the SI (see Section 2.3).

In study 2, 60 unselected individuals (11 males, 49 females; mean age $=21, \mathrm{SD}=2.04$, range $=18-28$ years) of the original sample were invited to take part in a pain induction experiment, and completed the questionnaires once again. The participants verbally reported to the experimenter to be free from (chronic) physical or mental illnesses in both studies. All participants gave informed consent and received financial compensation for their participation. The experimental protocol was approved by the Medical Ethics Committee of Maastricht University/University Hospital Maastricht.

\subsection{Procedure}

All participants from study 1 were recruited at Maastricht University through advertisements and posters in the University building. They completed the questionnaires in small groups of approximately 10 persons in a room in the University building. Six months later, 60 participants from the original sample were randomly invited to take part in the pain induction study. The pain induction procedure consisted of an ischemic pain test, electrical stimulation, and heat pain stimulation that were presented in a counterbalanced order. Before the start of each pain test, anticipatory fear of pain was assessed. Participants rated the level of fear that they thought would be associated with the pain test on a $100-\mathrm{mm}$ visual analogue scale (VAS) with anchors "no fear at all' to 'very fearfull'. Pain tolerance scores were obtained for each of the three pain induction procedures. Pain tolerance in the ischemic pain test was measured as the maximum amount of time (milliseconds) that people could endure performing handgrip exercises while pressure on their forearm was sustained on $160 \mathrm{mmHG}$ through the cuff of a sphygmomanometer. In the electrical stimulation test, pain tolerance was defined as the maximum stimulus intensity $(\mathrm{mA})$ that was reached before participants indicated that pain tolerance was reached. The heat pain stimulation test measured pain tolerance as the maximum temperature $\left({ }^{\circ} \mathrm{C}\right)$ that participants could tolerate before they pushed a button to reduce temperature back to baseline level (for details on the pain induction procedure see Roelofs et al., 2005).

\subsection{Measures}

The Sensitivity Index (SI) includes 39 items and consists of pooled items of three subscales, which tap AS (16 items), IS (11 items), and FNE (12 items). The English version of the SI (Taylor, 1993) was translated into Dutch in a state-of-the-art manner, involving back translation, after which the item content was checked against the original content. AS was measured by the Anxiety Sensitivity Index (ASI; Peterson and Heilbronner, 1987). This self-report measure consists of 16 statements that assert the negative consequences of experiencing anxiety (e.g., 'It scares me when my heart beats rapidly'). The ASI has been shown to be a reliable and stable measure of the fear of anxiety with Cronbach's $\alpha$ above 0.88 and test-retest correlations above 0.70. (Peterson and Heilbronner, 1987; Reiss, 1991; Rodriguez et al., 2004; Sandin et al., 2001). IS was measured with the Injury/illness Sensitivity Index (ISI; Taylor, 1993), containing 6 items pertaining to the fear of illness (e.g., 'I get scared if I think I'm coming down with an illness') and 5 items referring to the fear of injury (e.g., 'The thought of injury terrifies me'). Recent results of a factor analytic study on the ISI scale (Carleton et al., 2005) revealed two factors - Fear of Illness (7 items) and Fear of Injury (4 items) - that load onto a single higher order factor (i.e., injury/illness sensitivity or physical harm). The higher order factor of injury/illness sensitivity accounted for $74.3 \%$ of the variance in the lower-order factors and showed good simple structure with salient loadings of 0.86 for both the fear of Illness and Fear of Injury lower-order factors. The same study also proved the ISI to possess adequate reliability, with an $\alpha$ coefficient for the ISI total (11 items) of 0.89 . FNE was measured with the 12-item version of the Fear of Negative Evaluation Scale (Leary, 1983). This scale also has satisfactory reliability and validity, and taps fear of situations related to public observable behaviour and evaluation situations (e.g., 'I worry about what kind of impression I make on people'). Taylor adjusted the response format of the Fear of Negative Evaluation Scale such that participants rated all items of the SI using a 5-point Likert scale ranging from 1 (very little) to 5 (very much). The FNE had good internal consistency in this adapted format as well (Cronbach's $\alpha$ above 0.80) (Taylor, 1993).

The Pain Anxiety Symptoms Scale (PASS; McCracken et al., 1992) is a 40-item self-report measure that measures pain-related fear. The PASS was originally developed for chronic pain patients, but it has proven to be applicable in pain free populations as well (e.g., Muris et al., 2001). The PASS consists of four subscales, measuring fearful appraisal of pain (e.g., 'I think that if my pain gets too severe, it will never decrease'), cognitive anxiety (e.g., 'During painful episodes it is difficult for me to think of anything besides the pain'), physiological anxiety (e.g., 'Pain seems to cause my heart to pound or race'), and escape/avoidance behaviour (e.g., 'I try to avoid activities which cause pain'). The items are rated on a 6-point Likert scale ranging from 0 (never) to 5 
(always). The validity as well as the reliability of this measure has been well established in several studies (Osman et al., 1994; Roelofs et al., 2004).

The Fear of Pain Questionnaire (FPQ: McNeil and Rainwater, 1998) was specifically developed to measure fear of pain in a non-chronic pain population. It is a 30-item measure that assesses fear of severe pain (e.g., 'Breaking your leg'), minor pain (e.g., 'Getting a papercut on your finger'), and medical pain (e.g., 'Receiving an injection in your hip/buttocks'). The items are scored on a 5-point Likert scale ranging from 1 (not at all) to 5 (extreme). The psychometric properties of the English as well as the Dutch version (Peters, Van Damme, Goubert, Vlaeyen and Crombez, unpublished manuscript) of the FPQ are satisfactory (McNeil and Rainwater, 1998; Roelofs, 2005).

The Pain Catastrophizing Scale (PCS; Sullivan et al., 1995) taps pain catastrophizing, which is defined as 'an exaggerated orientation towards pain'. Participants need to take painful past experiences in mind, and subsequently indicate on a 5-point scale ranging from 0 (not at all) to 4 (all the time) to what extent they experienced each of 13 feelings and thoughts during that pain (e.g., 'I feel as if I can't take this anymore'). The original and Dutch version of the PCS have proven to be reliable and valid measures (Osman et al., 1997; Severeijns et al., 2002; Van Damme et al., 2002).

The State-Trait Anxiety Inventory - trait form (STAI-t; Spielberger et al., 1970) contains 20 items that tap a general anxiety disposition (e.g., 'I worry too much about unimportant things'). Participants have to indicate on a 4-point Likert scale, ranging from 1 (almost never) to 4 (almost always), to what extent these statements apply to them. A high score on this scale reflects a high general anxiety disposition. The original and Dutch versions (Ploeg van der et al., 1980) have proven to be reliable and valid measures.

\subsection{Statistical analyses}

We performed an exploratory factor analysis on the SI to see whether we could replicate the three-factor solution reported by Taylor (1993). The internal consistency was calculated using Cronbach's $\alpha$ for all subscales separately as well as for the whole SI. The total amount of variance in trait anxiety that was explained by the three fundamental fears was calculated by means of a simple linear regression analysis, in which all three fears were first entered independently into the model, and afterwards were tested simultaneously in the final model.

The association between the fundamental fears and trait anxiety and pain catastrophizing was examined with a stepwise linear regression analysis in which trait anxiety was entered in the first step and the predictors of interest (AS, IS, FNE) were simultaneously entered in the second step. The same analyses were performed to examine the unique predictive value of the three fundamental fears relative to pain tolerance and anticipatory fear of pain in the pain induction procedure.

\section{Results}

\subsection{Study 1}

\subsubsection{Factor analysis}

The Kaiser-Meyer-Olkin Measure of Sampling Adequacy of 0.92 indicated that the items of the SI were suitable for factor analysis. The items were subsequently submitted to a principal components analysis with oblique (oblimin) rotation with Kaiser normalization. An oblimin rotation allows the obtained factors to be intercorrelated. Cattel's Scree test revealed three factors to be extracted, which accounted for $52 \%$ of the total variance. The factor loadings are shown in Table 1. This 3 -factor solution corresponded with the three factors as originally proposed by Taylor (1993): Fear of Negative Evaluation (Factor 1), Anxiety Sensitivity (Factor 2) and Injury/illness Sensitivity (Factor 3). Correlations between the three factors were low to moderate, with $r=0.26$ for the correlation between FNE and IS, $r=0.40$ for the correlation between AS and IS, and $r=0.37$ for the correlation between AS and FNE.

Taking salient loadings as those $\geqslant 0.30$, Table 1 shows that each factor corresponds to a fundamental fear. However, some ASI items do load on other factors (items $13,14)$ or have secondary loadings on another factor (items 34, 36). Furthermore, two ASI items do not load on any of the three factors at all (items 29, 38). Four items (items 13, 14, 29, 36) are problematic in both the study of Taylor and the current study. Item 38, as it was formulated in the Dutch translation, appeared to deviate from the original item after the back translation, which can explain the fact that it doesn't load on any factor in the current study. This item has been changed in the most recent Dutch version. We created a reconstructed version of the SI in which the five problematic items were removed. Item 34 was left in the scale and assigned to the ASI subscale on theoretical grounds. All further analyses that are reported in this article were performed with the reconstructed version of the scale, although we also performed concordant analyses with the original scales in order to detect possible beneficial or detrimental effects of working with the original versus the reconstructed scale. Any deviations between both versions will be reported, if present.

\subsubsection{Descriptive statistics and internal consistencies of the sensitivity index}

Mean scores on the SI for both males and females are summarized in Table 2. Possible gender differences were investigated by means of independent sample $t$-tests for 
Table 1

Principal components analysis on the sensitivity index: factor loadings for the three-factor solution

\begin{tabular}{|c|c|c|c|c|}
\hline \multirow[t]{2}{*}{ Item - Scale } & \multirow[t]{2}{*}{ Item description } & \multicolumn{3}{|c|}{ Factors } \\
\hline & & FNE & AS & IIS \\
\hline $4-\mathrm{FNE}$ & I am concerned about other people's opinions of me & 0.92 & -0.04 & 0.02 \\
\hline $2-\mathrm{FNE}$ & I worry about what kind of impression I make on people & 0.92 & 0.05 & -0.03 \\
\hline $9-\mathrm{FNE}$ & I worry what other people will think of me even when I know it doesn't make any difference & 0.90 & -0.07 & 0.00 \\
\hline $3-\mathrm{FNE}$ & I am afraid that people will find fault with me & 0.87 & -0.05 & 0.05 \\
\hline $1-\mathrm{FNE}$ & Sometimes I think I am too concerned with what other people think of me & 0.86 & -0.02 & -0.08 \\
\hline $7-\mathrm{FNE}$ & I am usually worried about the kind of impression I make & 0.86 & 0.05 & 0.04 \\
\hline $5-\mathrm{FNE}$ & When I am talking to someone, I worry about what they may be thinking of me & 0.85 & -0.13 & 0.09 \\
\hline $12-\mathrm{FNE}$ & If I now that someone is judging me, it tends to bother me & 0.83 & -0.13 & 0.00 \\
\hline $10-\mathrm{FNE}$ & It bothers me when people form an unfavourable impression of me & 0.81 & -0.05 & 0.12 \\
\hline $6-\mathrm{FNE}$ & I am afraid that others will not approve of me & 0.80 & 0.15 & 0.04 \\
\hline $8-\mathrm{FNE}$ & I am frequently afraid of other people noticing my shortcomings & 0.73 & 0.14 & 0.08 \\
\hline $11-\mathrm{FNE}$ & I often worry that I will say or do the wrong things & 0.71 & 0.22 & -0.11 \\
\hline $28-\mathrm{ASI}$ & It scares me when I feel faint & 0.05 & 0.79 & -0.01 \\
\hline $39-\mathrm{ASI}$ & It scares me when I feel shaky & 0.00 & 0.72 & 0.09 \\
\hline $37-\mathrm{ASI}$ & It scares me when I become short of breath & 0.09 & 0.72 & -0.06 \\
\hline $27-$ ASI & It scares me when my heart beats rapidly & -0.03 & 0.72 & 0.04 \\
\hline $32-\mathrm{ASI}$ & When my stomach is upset, I worry that I might be seriously ill & -0.12 & 0.70 & 0.11 \\
\hline $33-\mathrm{ASI}$ & When I cannot keep my mind on a task, I worry that I might be seriously ill & -0.00 & 0.69 & -0.00 \\
\hline $31-\mathrm{ASI}$ & When I notice that my heart is beating rapidly, I worry I might have a heart attack & 0.02 & 0.60 & 0.11 \\
\hline $35-\mathrm{ASI}$ & When I am nervous, I worry that I might be mentally ill & 0.07 & 0.58 & -0.04 \\
\hline $30-\mathrm{ASI}$ & It scares me when I am unable to keep my mind on a task & 0.17 & 0.55 & 0.00 \\
\hline $25-\mathrm{ASI}$ & It scares me when I am nauseous & -0.03 & 0.47 & 0.26 \\
\hline $36-\mathrm{ASI}$ & It scares me when I am nervous & 0.33 & 0.39 & -0.08 \\
\hline $34-\mathrm{ASI}$ & Unusual body sensations scare me & 0.18 & 0.36 & 0.37 \\
\hline $14-\mathrm{ASI}$ & It is important to me to stay in control of my emotions & 0.30 & 0.19 & -0.06 \\
\hline $13-\mathrm{ASI}$ & It is important for me not to appear nervous & 0.41 & -0.02 & 0.00 \\
\hline $29-\mathrm{ASI}$ & It embarrasses me when my stomach growls & 0.25 & 0.25 & 0.09 \\
\hline $38-\mathrm{ASI}$ & Other people notice when I feel shaky & 0.16 & 0.09 & 0.18 \\
\hline $21-$ ISI & It would be awful to be injured in any way & 0.05 & -0.21 & 0.84 \\
\hline $15-$ ISI & I am frightened of being injured & -0.05 & 0.13 & 0.81 \\
\hline $16-$ ISI & The thought of injury terrifies me & 0.09 & -0.10 & 0.72 \\
\hline $18-$ ISI & The thought of physical illness scares me & -0.09 & 0.19 & 0.68 \\
\hline $24-$ ISI & I get scared if I think I am coming down with an illness & 0.02 & 0.18 & 0.65 \\
\hline $17-$ ISI & I worry about becoming physically ill & -0.09 & 0.33 & 0.62 \\
\hline $26-$ ISI & I can't stand the thought of being injured & 0.03 & 0.10 & 0.62 \\
\hline $20-$ ISI & I worry that I might get a serious physical illness in the future & 0.03 & 0.24 & 0.55 \\
\hline 19 - ISI & I worry about being injured & -0.05 & 0.29 & 0.47 \\
\hline $22-$ ISI & It would be awful to have a serious physical illness & 0.05 & -0.16 & 0.48 \\
\hline \multirow[t]{3}{*}{$23-$ ISI } & I worry about my physical health & 0.08 & 0.28 & 0.30 \\
\hline & Eigenvalue & 12.9 & 5.1 & 2.3 \\
\hline & Variance $(\%)$ & 33.2 & 13.2 & 6.0 \\
\hline
\end{tabular}

Note. ASI, Anxiety Sensitivity; ISI, Illness/injury Sensitivity; FNE, Fear of Negative Evaluation. Salient loadings $\geqslant|0.30|$ are listed in boldface type.

both test times separately. No differences on either the SI or the subscales were found. To evaluate the internal consistency of the SI, Cronbach's $\alpha$ s were computed. All scales had excellent reliability with $\alpha$ s of $0.94,0.88,0.88$, and 0.96 for the SI, the ASI, the ISI, and the FNE, respectively.

Table 2

Descriptive statistics of the sensitivity index and its three subscales in study 1

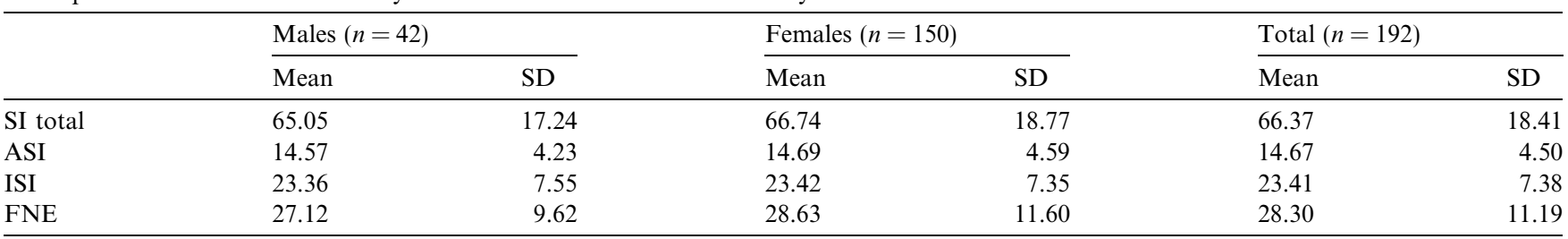

Note. SI total, Sensitivity Index, total score; ASI, Anxiety Sensitivity Index (the five problematic items excluded); ISI, Illness/injury Sensitivity Index; FNE, Fear of Negative Evaluation Scale. 
Table 3

Results of regression analyses with trait anxiety (STAI-t) as dependent variable

\begin{tabular}{lrccccc}
\hline \multicolumn{1}{c}{$\beta$} & $R^{2}$ & Adj. $R^{2}$ & $F$ & df & $p$ \\
\hline $\begin{array}{l}\text { Model 1 } \\
\text { FNE }\end{array}$ & 0.59 & 0.35 & 0.34 & 102.19 & 1,190 & 0.000 \\
$\begin{array}{l}\text { Model 2 } \\
\text { AS }\end{array}$ & 0.46 & 0.22 & 0.21 & 52.03 & 1,190 & 0.000 \\
Model 3 & & & & & & \\
IS & 0.23 & 0.06 & 0.05 & 11.04 & 1,190 & 0.001 \\
$\begin{array}{l}\text { Model 4 } \\
\text { FNE }\end{array}$ & 0.48 & 0.41 & 0.40 & 43.30 & 3,188 & .000 \\
AS & 0.32 & & & & & \\
IS & -0.12 & & & & & \\
\hline
\end{tabular}

Note. FNE, Fear of Negative Evaluation; AS, Anxiety Sensitivity; IS, Injury/illness sensitivity.

\subsubsection{Fundamental fears and trait anxiety}

The contribution of the factors in the explanation of trait anxiety was explored with linear regression analysis (Table 3). We first examined the separate contribution of AS, IS, and FNE in three separate regression models with trait anxiety (STAI-t) as dependent variable. The Variance Inflation Factors (VIF) ranged between values of 1.61 and 1.80 , indicating no severe collinearity between the independent measures. These analyses showed that FNE, AS, and IS accounted independently from each other for $34 \%, 21 \%$, and $0.05 \%$ of the variance of trait anxiety. Next, the final model was created in which all three fears were entered simultaneously as predictors in the model. A total of $40 \%$ of the variance in trait anxiety was explained by the three fundamental fears together; but, whereas both FNE and AS share sufficient variance with trait anxiety, IS does not significantly contribute to it in the final regression model.

\subsubsection{Fundamental fears, fear of pain, and pain catastrophizing}

The differential contribution of AS, IS, and FNE to the explanation of the pain-related measures was examined with linear regression analysis. In these analyses, trait anxiety was entered in the first block of the model, and the three factors - AS, IS, and FNE - were inserted in the second block. Entering trait anxiety in the first step of the analysis allows us to disentangle the specific influences of the fundamental fears from the overlapping explanations through trait anxiety. All VIF's were below 3 (ranging between 1.63 and 1.96), indicating no severe multi-collinearity between the independent variables. Table 4 shows that IS is the only significant predictor of fear of pain and pain catastrophizing. Both AS and IS are significant predictors of the PASS total score.

In order to test for differences in predictive value of both AS and IS for the dependent measures, we tested the magnitude of the partial correlation coefficients against each other. A partial correlation coefficient reflects the specific association between the predictor and the dependent variable, while the influence of the other predictor is controlled for. The comparison between the partial correlations between the ASI and the PCS on the one hand and the ISI and the PCS on the other hand was significant $(z=-4.89 ; \mathrm{df}=190 ; p<0.01)$, indicating that the ISI was the best predictor for pain catastrophizing. The partial correlations between the ASI and the ISI with the FPQ also differed significantly from each other $(z=-5.02$; $\mathrm{df}=190 ; p<0.001)$. Comparison of the partial correlations for AS and IS with the PASS revealed no significant effects. We subsequently performed a post hoc regression analysis on the four subscales of the PASS. Comparison of the partial correlation coefficients with the subscales of the PASS showed that IS (partial $r=0.34$ ) was more strongly re-

Table 4

Results of regression analyses with fear of negative evaluation, anxiety sensitivity, and injury/illness sensitivity as predictors in step 2 of fear of pain measures, and trait anxiety entered in step 1

\begin{tabular}{|c|c|c|c|c|c|c|c|c|c|}
\hline Dependent variable & Step & Variable entered & $R^{2}$ & $\Delta R^{2}$ & $\Delta F$ & $\mathrm{df}$ & $p$ & $B$ (Step 2) & Part $r$ \\
\hline \multirow[t]{4}{*}{ FPQ } & 1 & STAI-t & 0.02 & 0.02 & 5.63 & 1,190 & 0.019 & -0.03 & -0.02 \\
\hline & 2 & FNE & 0.23 & 0.22 & 16.68 & 3,187 & 0.000 & 0.15 & 0.14 \\
\hline & & AS & & & & & & 0.03 & 0.02 \\
\hline & & IS & & & & & & $0.40^{* *}$ & 0.34 \\
\hline \multirow[t]{4}{*}{ PCS } & 1 & STAI- $t$ & 0.14 & 0.14 & 30.00 & 1,190 & 0.000 & $0.21^{*}$ & 0.20 \\
\hline & 2 & FNE & 0.40 & 0.26 & 26.91 & 3,187 & 0.000 & 0.00 & 0.00 \\
\hline & & AS & & & & & & 0.12 & 0.11 \\
\hline & & IS & & & & & & $0.45^{* *}$ & 0.41 \\
\hline \multirow[t]{4}{*}{ PASS } & 1 & STAI-t & 0.16 & 0.16 & 35.77 & 1,190 & 0.000 & $0.18^{*}$ & 0.19 \\
\hline & 2 & FNE & 0.46 & 0.30 & 34.20 & 3,187 & 0.000 & -0.05 & -0.05 \\
\hline & & AS & & & & & & $0.36^{* *}$ & 0.33 \\
\hline & & IS & & & & & & $0.32^{* *}$ & 0.31 \\
\hline
\end{tabular}

Note. STAI-t, Spielberger's State-Trait Anxiety Inventory (Trait version); AS, Anxiety Sensitivity; IS, Illness/Injury Sensitivity; FNE, Fear of Negative Evaluation; FPQ, Fear of Pain Questionnaire; PCS, Pain Catastrophizing Scale; PASS, Pain Anxiety Symptoms Scale.

${ }_{\text {** }}^{*} p<0.01$.

** $p<0.001$. 
Table 5

Results of regression analyses with fear of negative evaluation, anxiety sensitivity, and injury/illness sensitivity as predictors in step 2 of pain tolerance and anticipatory fear of pain, and trait anxiety entered in step 1

\begin{tabular}{|c|c|c|c|c|c|c|c|c|c|}
\hline Dependent variable & Step & Variable entered & $R^{2}$ & $\Delta R^{2}$ & $\Delta F$ & df & $p$ & $\beta$ (Step 2) & Part $r$ \\
\hline \multirow[t]{4}{*}{ Fear ischemic } & 1 & STAI-t & 0.06 & 0.06 & 3.54 & 1,58 & 0.065 & 0.13 & 0.10 \\
\hline & 2 & FNE & 0.15 & 0.09 & 1.97 & 3,55 & 0.13 & -0.09 & -0.07 \\
\hline & & AS & & & & & & 0.06 & 0.06 \\
\hline & & IS & & & & & & $0.27^{* *}$ & 0.27 \\
\hline \multirow[t]{4}{*}{ Fear electrical } & 1 & STAI-t & 0.12 & 0.12 & 7.69 & 1,58 & 0.007 & 0.26 & 0.20 \\
\hline & 2 & FNE & 0.17 & 0.06 & 1.27 & 3,55 & 0.29 & 0.00 & 0.00 \\
\hline & & AS & & & & & & -0.04 & -0.03 \\
\hline & & IS & & & & & & $.27^{*}$ & 0.25 \\
\hline \multirow[t]{4}{*}{ Fear heat } & 1 & STAI-t & 0.01 & 0.01 & 0.61 & 1,58 & 0.44 & 0.00 & 0.00 \\
\hline & 2 & FNE & 0.18 & 0.17 & 3.88 & 3,55 & 0.01 & -0.09 & -0.07 \\
\hline & & AS & & & & & & -0.04 & -0.04 \\
\hline & & IS & & & & & & $0.46^{* * *}$ & 0.40 \\
\hline \multirow[t]{4}{*}{ Tolerance ischemic } & & STAI-t & 0.00 & 0.00 & 0.02 & 1,58 & 0.88 & 0.01 & 0.01 \\
\hline & & FNE & 0.06 & 0.06 & 1.16 & 3,55 & 0.33 & 0.17 & 0.13 \\
\hline & & AS & & & & & & -0.08 & -0.06 \\
\hline & & IS & & & & & & -0.21 & -0.19 \\
\hline \multirow[t]{4}{*}{ Tolerance electric } & & STAI-t & 0.04 & 0.04 & 2.13 & 1,58 & 0.15 & -0.13 & -0.10 \\
\hline & & FNE & 0.13 & 0.09 & 1.96 & 3,55 & 0.13 & 0.24 & 0.19 \\
\hline & & AS & & & & & & -0.24 & -0.18 \\
\hline & & IS & & & & & & -0.18 & -0.16 \\
\hline \multirow[t]{4}{*}{ Tolerance heat } & & STAI-t & 0.06 & 0.06 & 4.11 & 1,58 & 0.047 & -0.24 & -0.18 \\
\hline & & FNE & 0.11 & 0.05 & 0.99 & 3,55 & 0.41 & 0.22 & 0.17 \\
\hline & & AS & & & & & & -0.22 & -0.17 \\
\hline & & IS & & & & & & -0.03 & -0.03 \\
\hline
\end{tabular}

Note. STAI-t, Spielberger's State-Trait Anxiety Inventory (Trait version); AS, Anxiety Sensitivity; IS, Illness/Injury Sensitivity; FNE, Fear of Negative Evaluation.

${ }^{*} p<0.10$.

${ }^{* *} p<0.05$.

*** $p<0.001$.

lated to the escape/avoidance subscale than AS (partial $r=0.12)(z=-3.57 ; p<0.001)$. The PASS fearful appraisal of pain subscale showed a trend towards a stronger association with IS (partial $r=0.41$ ) than with AS (partial $r=0.30$ ), but this difference was not significant $(z=-1.78 ; p=0.075)$. AS, on the other hand, was a stronger predictor of the PASS physiological anxiety subscale, showing partial correlation coefficients of 0.36 and 0.07 with AS and IS, respectively $(z=4.73$; $p<0.001)$. The PASS cognitive anxiety subscale showed partial correlation coefficients of 0.26 and 0.21 with AS and IS, respectively, and this did not result in a significant difference between both predictors for this subscale. FNE did not contribute significantly to the prediction of any of the four PASS subscales.

\subsection{Study 2}

\subsubsection{Predictive validity of fundamental fears for responses to pain induction}

The three fundamental fears were correlated with anticipated fear for each of the three pain induction procedures. FNE and AS did not correlate with anticipatory fear, whereas IS showed a significant correlation with fear of the ischemic pain test $(r=0.36, p<0.01)$, fear of electrical stimulation $(r=0.35, p<0.01)$, and fear of heat pain stimulation $(r=0.41, p<0.01)$. Regression analyses (VIF's ranging between 1.34 and 1.93) also showed that IS contributed most in the explanation of anticipatory fear of pain for the three pain induction procedures (Table 5). For pain tolerance, mixed results were found. None of the fundamental fears correlated with time until termination of the ischemic pain test. Pain tolerance for the electrical stimulation correlated $-0.26(p<0.05)$ with AS and -0.27 $(p<0.05)$ with IS. Pain tolerance for heat pain stimulation showed a significant correlation of $-0.27(p<0.05)$ with AS only. When all three fundamental fears were entered simultaneously in a regression analysis after controlling for trait anxiety (for the three pain tests separately), neither AS, IS or FNE contributed significantly to the explanation of pain tolerance (Table 5).

\section{Discussion}

The main aim of this research was to examine the contribution of fundamental fears to fear of pain and pain 
catastrophizing. However, first we evaluated the psychometric properties of the instrument that measures fundamental fears, the Sensitivity Index (SI). The SI showed good to excellent internal consistencies for the scale as a whole and for the three subscales (ASI, ISI, FNE). The factor analysis on the Dutch version of the SI resulted in a 3-factor structure, thereby replicating Taylor's findings (1993). The three factors were labelled as corresponding to FNE, AS, and IS. The three factors together explained $52 \%$ of the total variance, but correlated low among each other. This indicates that it is likely that the factors do measure distinct constructs. The magnitude of the loadings revealed that most items were good representatives for the scales they belonged to. However, some items of the ASI had secondary loadings or loaded onto another factor, whereas two items didn't load substantially on any factor at all. This was also the case in Taylor's study, and raises questions about the applicability of some of the items. We created a revised version of the ASI scale, in which five problematic items were omitted, and this was used throughout all further analyses in this study. As an additional check, we also conducted concordant analyses with the original ASI scale to check whether results would deviate from our findings when the problematic items were kept in the scale. These concordant analyses revealed the same pattern of results as the one that is reported in this manuscript, and indicates that although some items appear bad representatives of the scale in the factor analyses, their inclusion does not affect the value of the ASI in this study. We therefore suggest considering the use of an adapted version of the ASI in subsequent studies. Throughout the literature, there have been several suggestions for dealing with the dubious items of the ASI through the use of revised scales. In line with our findings, some authors already suggested the use of a shortened version of the ASI, consisting of two lower-order factors (fear of somatic sensations and fear of loss of control (Blais et al., 2001; Schmidt and Joiner, 2002; Keogh and Asmundson, 2004). Other studies suggest to use an expanded version of the ASI, consisting of 36 items, that support a four-factor structure of AS (beliefs about the harmful consequences of pain, fear of publicly observable anxiety reactions, fear of cognitive dyscontrol, and fear of somatic sensations without explicit consequences) (e.g. Taylor, 1995; Deacon et al., 2003).

Following Taylor (1993), we also examined the relationship between the three factors of the SI and trait anxiety as measured by the STAI-t. According to the hierarchical model proposed by Lilienfeld (1996) and later extended by Keogh and Asmundson (2004), AS, IS, and FNE form lower-order factors that are nested within the higher-order factor of trait anxiety. The three fundamental fears do indeed explain variance in trait anxiety when their contribution to trait anxiety is examined independently from each other. The values of the
Beta weights indicate, however, that the ability to account for variance in trait anxiety is smaller for IS than for the other two fears. When all three fears were subsequently entered together in the regression model, IS did not contribute to trait anxiety at all, in contrast to FNE and AS. This finding raises question about whether IS is indeed a lower order factor of trait anxiety, as one would expect that IS should explain unique variance in trait anxiety that is not accounted for by AS and FNE. Further investigation of the association between IS and trait anxiety is clearly warranted. This should also include other measures of trait anxiety or anxiety disposition in addition to STAI-t, e.g. the Behavioural Inhibition Scale. It is possible that STAI-t does not encompass all aspects of fear or anxiety that people experience in daily life.

The strong relation between FNE and trait anxiety is a replication of Taylor's (1993) findings. Taylor stated that FNE probably is the most fundamental fear of the three, since it is responsible for many common fears, which are displayed most often in the daily society (e.g. social fears, animal fears, and general anxiety).

The main focus of study 1 concerned the differential contribution of AS and IS in the explanation of pain-related fear and pain catastrophizing. Results of the regression analyses showed that both IS and AS contribute to the explanation of pain-related fear and catastrophizing, whereas FNE does not contribute significantly to these fears. In accordance with our hypothesis, IS was a stronger predictor of fear of pain (FPQ) and pain catastrophizing (PCS) than AS. Both AS and IS were approximately equally predictive of PASS total scores. However, post hoc analyses on the subscales of the PASS indicated that AS and IS may be differentially related to some of the PASS subscales. Most notably, IS was significantly stronger associated to the escape/ avoidance subscale of the PASS than AS, whereas AS was significantly stronger related than IS to the physiological anxiety subscale. This may be a product of the item content of the different subscales. Items of the PASS physiological anxiety subscale concern the symptoms that are physiologically related to the experience of pain. This can explain the better prediction by AS, defined as the general fear of physical sensations. The PASS escape/avoidance subscale consists of items that possess the so-called 'harm-effect': the thought that pain is a predictor of a serious disorder or injury. This thought makes people engage in avoidance behaviour to avoid the development of injury.

In study 2, the differential predictive power of the fundamental fears was investigated for pain tolerance and anticipatory fear of pain for the three pain induction procedures separately. IS proved to be the only predictor for imminent fear of an impending pain stimulus. This unique association between IS and anticipatory fear of pain demonstrates that IS represents a specific sensitivity for 
the threat of pain and the fear of potential consequences that may go with injury and illness. This finding also supports the finding of an association between IS and pain catastrophizing and between IS and the escape/avoidance subscale of the PASS, since both of these measures also pertain to the fear and catastrophic appraisal of the forecast of pain. When examining the relation between the fundamental fears and pain tolerance, significant correlations were found for the electrical tolerance score with both AS and IS, and the thermal heat tolerance score with AS. However, in the regression analyses, pain tolerance was not predicted by the fundamental fears in any of the pain induction procedures. This finding may be ascribed to the characteristics of the pain tests and the lack of ecological validity that originates from them. Participants were aware that they would take part in a controlled study, in which pain duration and pain intensity would be limited (in comparison to real-life situations). Further investigation on the relation between the fundamental fears and the objective and subjective pain measures is therefore warranted.

The current study is the first to address the role of IS in predicting pain-related variables. However, some limitations should be taken into account when interpreting these results. Although informative, the present findings are still preliminary and resulting from multiple regression analyses, thereby leaving room for inflated type I errors. Subsequent research should further validate the relationships and findings that are currently discussed, using more elaborative statistical approaches, like structural equation modelling, that allow deriving conclusions on hierarchical relations between the variables, thereby accounting for the dependency between the dependent variables. The use of more sophisticated analyses can also give a clearer insight into the nature of the relationship between the fundamental fears (particularly IS) and trait anxiety. The absence of predictive power of IS for trait anxiety might raise questions on the value of the STAI-t as an accurate measure for trait anxiety. Second, the lack of predictive power of the fundamental fears for pain tolerance measures needs further attention in subsequent studies that should try to establish realistic pain situations. Third, it would be interesting to examine the association with the Tampa Scale of Kinesiophobia (TSK). The TSK is less suitable in a pain-free population, but especially with respect to pain-related fear, identifying the association between IS and the TSK would be valuable. It would furthermore add value to the SI research to test its predictive value in experimental paradigms, comparing the self-report data with more explicit or implicit behavioural, psychophysiological, and cognitive measures.

Despite these limitations, the current study is the first to provide evidence for the suggestion that IS might be equally or even more important than AS when identifying predictive traits in the (chronic) pain process.
Although AS has provided valuable information in pain research, IS possibly forms a more relevant, if not crucial, construct in this area. Future research should therefore more thoroughly investigate the differential contributions of AS and IS to pain-related fear and pain catastrophizing, as well as to the pain process in general.

\section{Acknowledgements}

The authors would like to thank R. Nicholas Carleton for his help with the evaluation of the back translation of the SI. Furthermore, we are grateful to Judith Deutz and Joëlle Janssen for their help with the data collection.

This research was (partly) supported by a grant from the Netherlands Organisation for Scientific Research (NWO: grant no. 015-001-050).

Dr. Asmundson is supported by a Canadian Institutes of Health Research Investigator Award.

\section{References}

Asmundson GJG, Norton GR. Anxiety sensitivity in patients with physically unexplained chronic back pain: A preliminary report. Behav Res Ther 1995;33:771-7.

Asmundson GJG, Taylor S. Role of anxiety sensitivity in pain-related fear and avoidance. J Behav Med 1996;19:577-86.

Asmundson GJG, Wright KD, Hadjistavropoulos HD. Anxiety sensitivity and disabling chronic health conditions: state of the art and future directions. Scand J Behav Ther 2000;29: $100-17$.

Blais MA, Otto MW, Zucker BG, McNally RJ, Schmidt NB, Fava M, et al. The Anxiety Sensitivity Index: item analysis and suggestions for refinement. J Pers Assess 2001;77:272-94.

Carleton RN, Asmundson GJG, Taylor S. Fear of physical harm: factor structure and psychometric properties of the illness/injury sensitivity index. J Psychopathol Behav Assess 2005;27:235-41.

Deacon BJ, Abramowitz JS, Woods CM, Tolin DF. The Anxiety Sensitivity Index - revised: psychometric properties and factor structure in two nonclinical samples. Behav. Res. Ther. 2003;41:1427-49.

Greenberg J, Burns JW. Pain Anxiety among chronic pain patients: specific phobia or manifestation of anxiety sensitivity? Behav Res Ther 2003;41:223-40.

Keogh E, Asmundson GJG. Negative affectivity, catastrophizing, and anxiety sensitivity. In: Asmundson GJG, Vlaeyen JWS, Crombez $G$, editors. Understanding and treating fear of pain. New York: Oxford University Press; 2004. p. 91-115.

Keogh E, Birkby J. The effect of anxiety sensitivity and gender on the experience of pain. Cognition Emotion 1999;13:813-29.

Keogh E, Mansoor L. Investigating the effects of anxiety sensitivity and coping on the perception of cold pressor pain in healthy women. Eur J Pain 2001;5:11-25.

Leary MR. A brief version of the Fear of Negative Evaluation Scale. Pers Soc Psychol B 1983;9:371-5.

Lilienfeld SO. Anxiety sensitivity is not distinct from trait anxiety. In: Rapee RM, editor. Current controversies in the anxiety disorders. New York: The Guilford Press; 1996. p. 228-44.

McCracken LM, Zayfert C, Gross RT. The Pain Anxiety Symptoms Scale: development and validation of a scale to measure fear of pain. Pain 1992;50:67-73. 
McNally RJ. Anxiety sensitivity is distinguishable from trait anxiety. In: Rapee RM, editor. Current controversies in the anxiety disorders. New York: The Guilford Press; 1996. p. 214-27.

McNeil DW, Rainwater AJ. Development of the Fear of Pain Questionnaire-III. J Behav Med 1998;21:389-410.

McWilliams LA, Cox BJ. How distinct is anxiety sensitivity from trait anxiety? A re-examination from a multidimensional perspective. Pers Ind Diff 2001;31:813-8.

Muris P, Vlaeyen JWS, Meesters C. The relationship between anxiety sensitivity and fear of pain in healthy adolescents. Behav Res Ther 2001;39:1357-68.

Osman A, Barrios FX, Kopper BA, Hauptmann W, Jones J, O'Neill E. Factor structure, reliability, and validity of the Pain Catastrophizing Scale. J Behav Med 1997;20:589-605.

Osman A, Barrios FX, Osman JR, Schneekloth R, Troutman JA. The pain anxiety symptoms scale: psychometric properties in a community sample. J Behav Med 1994;17:511-22.

Peterson RA, Heilbronner RL. The Anxiety Sensitivity Index: construct validity and factor analytic structure. J Anxiety Disord 1987;1:117-21.

Ploeg van der HM, Defares PB, Spielberger CD. Handleiding bij de Zelfbeoordelings Vragenlijst ZBV: Een nederlandstalige bewerking van de Spielberger State-Trait Anxiety Inventory STAI-DY. Amsterdam: Swets \& Zeitlinger B.V.; 1980.

Reiss S. Expectancy model of fear, anxiety, and panic. Clin. Psychol. Rev. 1991;11:141-53.

Reiss S. Trait anxiety: It's not what you think it is. J Anxiety Disord 1997;11(2):201-14.

Reiss S, Peterson RA, Gursky DM. Anxiety sensitivity, injury sensitivity, and individual differences in fearfulness. Behav Res Ther 1988;26:341-5.

Reiss S, Peterson RA, Gursky DM, McNally RJ. Anxiety sensitivity, anxiety frequency and the prediction of fearfulness. Behav Res Ther 1986;24:1-8.
Rodriguez BF, Bruce SE, Pagano ME, Spencer MA, Keller MB. Factor structure and stability of the Anxiety Sensitivity Index in a longitudinal study of anxiety disorder patients. Behav Res Ther 2004;42:79-91.

Roelofs J, McCracken LM, Peters ML, Crombez G, van Breukelen G, Vlaeyen JW. Psychometric evaluation of the Pain Anxiety Symptoms Scale (PASS) in chronic pain patients. J Behav Med 2004;27:167-83.

Roelofs J, Peters ML, Deutz J, Spijker C, Vlaeyen JWS. The Fear of Pain Questionnaire (FPQ): further psychometric examination in a non-clinical sample. Pain 2005;116: 339-346.

Sandin B, Chorot P, McNally RJ. Anxiety Sensitivity Index: normative data and its differentiation from trait anxiety. Behav Res Ther 2001;39:213-9.

Schmidt NB, Joiner TE. Structure of the Anxiety Sensitivity Index psychometrics and factor structure in a community sample. J Anxiety Disord 2002;16:33-49.

Severeijns R, van den Hout MA, Vlaeyen JWS, Picavet HSJ. Pain catastrophizing and general health status in a large Dutch community sample. Pain 2002;99:367-76.

Spielberger CD, Gorsuch RL, Lushene RE. State-trait anxiety inventory. Palo Alto: Consulting Psychologists Press; 1970.

Sullivan MJL, Bishop SR, Pivik J. The pain catastrophizing scale: development and validation. Psychol Assess 1995;7: 524-32.

Taylor S. The structure of fundamental fears. J Behav Ther Exp Psychiat 1993;24:289-99.

Taylor S. Anxiety sensitivity: theoretical perspectives and recent findings. Behav Res Ther 1995;33:243-58.

Van Damme S, Crombez G, Bijttebier P, Goubert L, Van Houdenhove B. A confirmatory factor analysis of the Pain Catastrophizing Scale: invariant factor structure across clinical and non-clinical populations. Pain 2002;96:319-24. 